\title{
Does going to an amusement park alleviate low back pain? A preliminary study
}

\section{Toshihiko Sakakibara \\ Zhuo Wang \\ Yuichi Kasai}

Department of Spinal Surgery and Medical Engineering, Mie University Graduate School of Medicine, Tsu City, Mie Prefecture, Japan
Correspondence: Yuichi Kasai 2-174 Edobashi, Tsu City, Mie Prefecture, 5|4-8507, Japan

$\mathrm{Tel}+8 \mathrm{I} 5923 \mathrm{I} 5022$

Fax +8I 59 23। 52।I

Email ykasai@clin.medic.mie-u.ac.jp
This article was published in the following Dove Press journal: Journal of Pain Research

16 October 2012

Number of times this article has been viewed

Background: Low back pain is often called nonspecific pain. In this type of low back pain, various emotions and stress are known to strongly affect pain perception. The purpose of this study is to investigate how the degree of low back pain changes in people with chronic mild low back pain when they are inside and outside of an amusement park where people are supposed to have physical and psychological enjoyment.

Methods: The subjects were 23 volunteers (13 males and 10 females) aged 18 to 46 years old with a mean age of 24.0 years who had chronic low back pain. Visual analog scale (VAS) scores of low back pain and salivary amylase levels (kIU/L) of all subjects were measured at five time points: immediately after getting on the bus heading for the amusement park; 10 minutes, 1 hour (immediately after boarding the roller coaster), and 3 hours (immediately after exiting the haunted house) after arriving at the amusement park; and immediately before getting off the bus returning from the park.

Results: The three VAS values in the amusement park (10 minutes, 1 hour, and 3 hours after arriving at the amusement park) measured were significantly lower $(P<0.05)$ when compared with the other two values measured immediately after getting on the bus heading for the amusement park and immediately before getting off the return bus. In salivary amylase levels, there were no statistically significant differences among the values measured at the five time points.

Conclusion: Low back pain was significantly alleviated when the subjects were in the amusement park, which demonstrated that enjoyable activities, though temporarily, alleviated their low back pain.

Keywords: low back pain, emotion, salivary alpha-amylase activity, enjoyment activities, psychological stress

\section{Introduction}

In Japan, there are many patients suffering from low back pain. The 2010/2011 National Livelihood Survey ${ }^{1}$ reports that the number of Japanese people with low back pain per 1000 population is $87.4(8.7 \%)$ in males and $117.9(11.8 \%)$ in females, a very large proportion indeed.

It has been reported that, while pain is exacerbated by physical and psychological stress, it is alleviated when doing something fun, such as listening to music and appreciating paintings. ${ }^{2-5}$ In particular, low back pain is often called nonspecific pain and various emotions and stresses are known to strongly affect pain perception. ${ }^{6}$ For example, it has been reported that music therapy alleviates postoperative pain whereas listening to unhappy music increases the pain, ${ }^{7}$ and that pain decreases when looking at pleasant pictures but it increases when looking at unpleasant pictures. ${ }^{8}$ Sports, daily 
exercise, and gymnastics are also effective in alleviating low back pain, ${ }^{9}$ but the most important thing is the notion of pleasure. In other words, when a person is engaged in enjoyable activities such as taking a bath, ${ }^{10}$ being absorbed in a hobby, or eating a favorite food, pain is assumed to be alleviated by various mechanisms, including cerebral and spinal modulation of pain by emotions and increased production of the brain hormone endorphin. ${ }^{3,8,11}$

In an effort to investigate how the degree of low back pain changes in people with chronic mild low back pain when they are inside and outside an amusement park where people are supposed to have physical and psychological enjoyment, we conducted the following study and herein report our findings.

\section{Methods}

The subjects were 23 volunteers (13 males and 10 females) aged 18 to 46 years old with a mean age of 24.0 years who had chronic low back pain. Chronic pain was defined as constant pain lasting for the past 3 months or longer with a pain intensity score of 20 or higher using the visual analog scale (VAS; 0-100 mm). Severe pain was defined as a VAS score of 60 or higher, mild pain as 20 to $<60$, and slight pain as $<20$. All participants of this study had VAS scores between 20 and $<60$ (ie, mild pain) during the preceding 3 months or longer.

The volunteers who participated in this study were recruited mainly from among students of our university by informing them in advance that the subjects would go to an amusement park by bus, that the degree of their low back pain would be investigated in that park, and that the bus fare and the amusement park ticket would be free. This study was conducted with the approval of the ethics committee of Mie University, Tsu City, Japan (No 2346) in advance, and we obtained consent to participate in this study from all subjects immediately before beginning the study. The Japanese Orthopedic Association Back Pain Evaluation Questionnaire (JOABPEQ) and Maudsley Personality Inventory (MPI) were administered to all subjects. Results of the JOABPEQ showed that none of the subjects had disabling low back pain. The MPI showed that none of the participants had any apparent personality test abnormalities.

Lumbar spinal magnetic resonance images (MRIs) of all subjects were taken, and the subjects were asked whether they liked amusement parks or not. Also, their VAS scores of low back pain and salivary amylase levels as a stress marker were measured in real time. VAS scores of low back pain were measured by having the subjects indicate the level of their low back pain on a $100 \mathrm{~mm}$ straight line at five time points: A point, immediately after getting on the bus heading for the amusement park; B point, 10 minutes after arriving at the amusement park; $\mathrm{C}$ point, 1 hour after arriving at the amusement park (immediately after boarding the roller coaster); D point, 3 hours after arriving at the amusement park (immediately after exiting the haunted house); and E point, immediately before getting off the bus returning from the park. Salivary amylase levels (kIU/L) were measured five times at the same time points (A-E points) when VAS scores were measured, by having all subjects place a measuring tip under the tongue for about 30 seconds and by using a portable Salivary Amylase Monitor ${ }^{\circledR}$ (NIPRO Corporation, Osaka, Japan).

Salivary amylase levels increase when the sympathetic nerve is excited, and therefore it should increase when under physical and psychological stress. ${ }^{12}$ Since this value would be significantly affected by food and drink, the participants were forbidden from eating and drinking for 30 minutes before each measurement.

For the control group, this study enrolled 18 individuals without low back pain, and their salivary amylase levels were also measured. In the statistical examination, the presence or absence of uniformity was tested with the Kruskal-Wallis test for the five measurements of the low back pain VAS scores and of the salivary amylase levels. When uniformity was not found, a post hoc analysis was performed using the Wilcoxon test with Bonferroni correction for multiple comparisons among the five measurements.

\section{Results}

The results of the lumbar spine MRIs of the 23 subjects showed that nine of them had very mild degeneration and/or bulging of the intervertebral disc and 14 of them had no abnormality. No abnormal finding such as an obvious herniated disc was observed in any of them. As regards the question of whether they liked amusement parks or not, all of them answered, "I like amusement parks."

The mean low back pain VAS score (Table 1) was 36.3 at the measuring point immediately after getting on the bus heading for the park (A point), <20.0 at all three measurements while in the amusement park (B, C, and D points), and 33.4 at the measuring point immediately before getting off the return bus (E point), showing that VAS scores were clearly lower when the participants were in the amusement park. When the Kruskal-Wallis test was performed, uniformity was not found in the data of all measurements, and the three VAS values of B, C, and D points were significantly 
Table I VAS scores and salivary amylase levels at each point in 23 subjects with low back pain

\begin{tabular}{llllll}
\hline Measured point & A & B & C & D & E \\
\hline Mean VAS score & $36.3 \pm 17.2$ & $15.7 \pm 10.5^{*}$ & $14.4 \pm 9.6^{*}$ & $14.7 \pm 10.8^{*}$ & $33.4 \pm 15.8$ \\
(range) & $(20.0-56.1)$ & $(0-27.2)$ & $(0-30.5)$ & $(0-26.5)$ & $(9.5-45.5)$ \\
Mean salivary amylase level & $16.7 \pm 14.0$ & $22.8 \pm 17.6$ & $24.0 \pm 27.2$ & $25.0 \pm 20.8$ & $15.8 \pm 10.0$ \\
(range) & $(3-47)$ & $(0-39)$ & $(0-45)$ & $(0-4 I)$ & $(0-31)$ \\
\hline
\end{tabular}

Notes: A point, immediately after getting on the bus heading for the park; B point, 10 minutes after arriving at the amusement park; $C$ point, I hour after arriving at the amusement park; D point, 3 hours after arriving at the amusement park; E point, immediately before getting off the bus returning from the park; *the three VAS scores of B, $C$, and $D$ points were significantly lower (all $P<0.05$ ) than the scores of $A$ and $E$ points.

Abbreviation: VAS, visual analog scale.

lower (all $P<0.05$ ) than the other two VAS values of A and E points. The data by severity of low back pain categorized by our definition are shown in Table 2 .

The mean salivary amylase level (Table 1 ) was 16.7 at A point, $\geq 20$ at $\mathrm{B}, \mathrm{C}$, and $\mathrm{D}$ points, and 15.8 at $\mathrm{E}$ point; thus, the values were generally higher when the subjects were in the amusement park. When the Kruskal-Wallis test was performed, uniformity was found in the data of all five measurements, indicating no significant difference in their salivary amylase levels.

The data of the control group (without low back pain), shown in Table 3, demonstrate no statistically significant differences among the five points. In the data of the salivary amylase levels, there are no significant differences between the low back pain group and the control, non-pain group.

\section{Discussion}

The results of our study revealed that the enjoyable activity of going to an amusement park alleviated, though temporarily, low back pain. There has been no other report in the past that actually took the subjects to an amusement park and measured their low back pain in real time, which makes our study valuable.

It may be well known that pain can be alleviated by concentrating on something fun or one's favorite pastime, and this idea is applied as distraction therapies in clinical

Table 2 The number of persons categorized at each level of severity of low back pain at each point

\begin{tabular}{llllll}
\hline & A & B & C & D & E \\
\hline No pain & 0 & 2 & 3 & I & 0 \\
Slight pain & 5 & 11 & 12 & 13 & 6 \\
Mild pain & 18 & 10 & 8 & 9 & 17 \\
Severe pain & 0 & 0 & 0 & 0 & 0 \\
\hline
\end{tabular}

Notes: Severe pain was defined as a visual analog score of 60 or higher, mild pain as 20 to $<60$, and slight pain as $<20$ in this study. A point, immediately after getting on the bus heading for the park; $B$ point, 10 minutes after arriving at the amusement park; C point, I hour after arriving at the amusement park; $D$ point, 3 hours after arriving at the amusement park; E point, immediately before getting off the bus returning from the park. practice with the use of music, images, movies, video games, and other tools for distraction. ${ }^{13-15}$ However, all of these tools typically involve virtual reality experiences and imagination. Real-life-experience studies on the effects of distraction have been rare, but include studies of pain reduction by touching animals in hospitals ${ }^{16}$ or by traveling to have real experience of amusement park attractions as in our study. In this study, the severity of chronic low back pain was mild in all participants with low back pain. We believe that the results of this study are noteworthy and are novel in that even mild low back pain was alleviated by amusement park experiences.

The possibility of a Hawthorne effect ${ }^{17,18}$ cannot be excluded if some participants knew the purpose of this experiment and were biased to report a decrease in low back pain immediately after an enjoyable activity. However, we told the subjects of this study only that they were going to get on a bus and go to an amusement park, take a ride on a roller coaster and go into a haunted house there, and then come back; we did not tell them anything about the objective of the study, such as evaluation of the association between low back pain and stress.

Shirasaki et a ${ }^{19}$ reported that the salivary amylase level was significantly correlated with VAS score, and we measured it assuming that this measurement could objectively evaluate the degree of pain. However, it is still controversial whether the salivary amylase level can serve as a marker of stress and pain. ${ }^{20,21}$ Actually, the values measured in the amusement park were higher in our study, and we could not find collateral evidence that pain and stress were alleviated in the park. Adam et $a^{22}$ reported that salivary amylase may reflect levels of emotional arousal including high arousal positive emotions (feeling strong, active, vigorous, excited), rather than being specific to stress or emotions of negative valence (angry, stressed, nervous, worried). Thus, the higher values of salivary amylase levels measured in this study when the participants were in the amusement park may also reflect excitement of the sympathetic nerve as a result of increased 
Table 3 VAS scores and salivary amylase levels at each point in subjects without low back pain

\begin{tabular}{llllll}
\hline Measured point & A & B & C & D & E \\
\hline Mean VAS score & $0.2 \pm 0.2$ & $0.2 \pm 0.1$ & $0.3 \pm 0.2$ & $0.3 \pm 0.2$ & $0.2 \pm 0.1$ \\
(range) & $(0-0.5)$ & $(0-0.5)$ & $(0-0.8)$ & $(0-0.7)$ & $(0-0.7)$ \\
Mean salivary amylase level & $18.3 \pm 16.0$ & $19.8 \pm 17.6$ & $19.8 \pm 18.2$ & $19.1 \pm 16.3$ & $17.3 \pm 15.0$ \\
(range) & $(2-37)$ & $(0-38)$ & $(0-39)$ & $(3-38)$ & $(3-33)$ \\
\hline
\end{tabular}

Note: There were no statistically significant differences among the five points.

Abbreviation: VAS, visual analog scale.

vigor on the part of the participants rather than an increased stress. As for the methods of saliva amylase measurements, unlike measurements in hospitals where quiet small rooms are available for participants to be alone for at least several minutes to assure comfortable resting to reduce the influence of physical activity and stress, individual participants in this study rested for several minutes in only a relatively quiet place within the constantly noisy amusement park before each saliva amylase measurement. Thus, a better environment for saliva amylase measurements with less physical activity and less stress may have provided better data. Moreover, it is supposed that measurements of calcitonin gene-related peptide (CGRP) in saliva ${ }^{23,24}$ are associated with chronic pain, and they may provide important data.

Limitations of this study include that the number of subjects was small, the subjects were only those with mild low back pain, the mean age of the studied group was rather low in this current study, and only those who liked amusement parks participated. Regrettably, we did not ask the study participants about whether they participated alone or with friends, or whether they had previously visited the amusement park, although these confounding factors could affect the study results.

In the future, we would like to increase the number of subjects to conduct similar studies in subjects with chronic low back pain with VAS scores $\geq 50$ and in subjects who do not like amusement parks. Further studies should be designed to analyze potential confounding factors and to evaluate the impact of pleasurable activities other than amusement parks for the purpose of confirming the robustness of our conclusion.

\section{Conclusion}

We investigated the degree of low back pain in 23 subjects with mild low back pain in real time when they were inside and outside an amusement park. The results showed that low back pain was significantly alleviated when the subjects were in the amusement park, which demonstrated that enjoyable activities, though temporarily, can alleviate low back pain.

\section{Disclosure}

The authors report no conflicts of interest in this work.

\section{References}

1. [Overview of National Livelihood Survey 2010]. Health and Welfare Statistics Association; 22. Available from: http://www.mhlw.go.jp/ toukei/saikin/hw/k-tyosa/k-tyosa10/dl/gaikyou.pdf. Tokyo: 2011. Accessed May 22, 2012. Japanese.

2. Lewis S, Holmes P, Woby S, Hindle J, Fowler N. The relationships between measures of stature recovery, muscle activity and psychological factors in patients with chronic low back pain. Man Ther. 2012; 17(1):27-33.

3. Zhao H, Chen AC. Both happy and sad melodies modulate tonic human heat pain. J Pain. 2009;10(9):953-960.

4. Good M, Anderson GC, Stanton-Hicks M, Grass JA, Makii M. Relaxation and music reduce pain after gynecologic surgery. Pain Manag Nurs. 2002;3(2):61-70.

5. Roy M, Lebuis A, Hugueville L, Peretz I, Rainville P. Spinal modulation of nociception by music. Eur J Pain. 2012;16(6):870-877.

6. Takeyachi Y, Konno S, Otani K, et al. Correlation of low back pain with functional status, general health perception, social participation, subjective happiness, and patient satisfaction. Spine (Phila Pa 1976) 2003;28(13):1461-1466.

7. Guétin S, Coudeyre E, Picot MC, et al. Effect of music therapy among hospitalized patients with chronic low back pain: a controlled, randomized trial. Ann Readapt Med Phys. 2005;48(5):217-224.

8. Roy M, Piché M, Chen JI, Peretz I, Rainville P. Cerebral and spinal modulation of pain by emotions. Proc Natl Acad Sci U S A. 2009;106(49):20900-20905.

9. Henchoz Y. Non-specific low back pain: are exercise and sporting activities recommended? Rev Med Suisse. 2011;7(286):612-616.

10. Balogh Z, Ordögh J, Gász A, Német L, Bender T. Effectiveness of balneotherapy in chronic low back pain - a randomized single-blind controlled follow-up study. Forsch Komplementarmed Klass Naturheilkd. 2005;12(4):196-201.

11. Franklin RG Jr, Adams RB Jr. The reward of a good joke: neural correlates of viewing dynamic displays of stand-up comedy. Cogn Affect Behav Neurosci. 2011;11(4):508-515.

12. Takai N, Yamaguchi M, Aragaki T, Eto K, Uchihashi K, Nishikawa Y. Effect of psychological stress on the salivary cortisol and amylase levels in healthy young adults. Arch Oral Biol. 2004;49(12):963-968.

13. Buhle JT, Stevens BL, Friedman JJ, Wager TD. Distraction and placebo: two separate routes to pain control. Psychol Sci. 2012;23(3): 246-253.

14. Jameson E, Trevena J, Swain N. Electronic gaming as pain distraction. Pain Res Manag. 2011;16(1):27-32.

15. Vilarreal EA, Brattico E, Vase L, Østergaard L, Vuust P. Superior analgesic effect of an acute distraction versus pleasant unfamiliar sounds and music: the influence of emotion and cognitive style. PloS One. 2012;7(1):e29397.

16. Urbanski BL, Lazenby M. Distress among hospitalized pediatric cancer patients modified by pet-therapy intervention to improve quality of life. J Pediatr Oncol Nurs. 2012;29(5):272-282. 
17. Wickström G, Bendix T. The "Hawthorne effect"- - what did the original Hawthorne studies actually show? Scand J Work Environ Health. 2000; 26(4):363-367.

18. De Amici D, Klersy C, Ramajoli F, Brustia L, Politi P. Impact of the Hawthorne effect in a longitudinal clinical study: the case of anesthesia. Control Clin Trials. Apr 2000;21(2):103-114.

19. Shirasaki S, Fujii H, Takahashi M, et al. Correlation between salivary alpha-amylase activity and pain scale in patients with chronic pain. Reg Anesth Pain Med. 2007;32(2):120-123.

20. Rohleder N, Nater UM, Wolf JM, Ehlert U, Kirschbaum C. Psychosocial stress-induced activation of salivary alpha-amylase: an indicator of sympathetic activity? Ann NY Acad Sci. 2004;1032:258-263.
21. Campos MJ, Raposo NR, Ferreira AP, Vitral RW. Salivary alphaamylase activity: a possible indicator of pain-induced stress in orthodontic patients. Pain Med. 2011;12(8):1162-1166.

22. Adam EK, Till Hoyt L, Granger DA. Diurnal alpha amylase patterns in adolescents: associations with puberty and momentary mood states. Biol Psychol. 2011;88(2-3):170-173.

23. Fischer HP, Eich W, Russell IJ. A possible role for saliva as a diagnostic fluid in patients with chronic pain. Semin Arthritis Rheum. 1998;27(6):348-359.

24. Jang MU, Park JW, Kho HS, Chung SC, Chung JW. Plasma and sliva levels of nurve growth factor and neuropeptides in chronic migraine patients. Oral Dis. 2011;17(2):187-193.

\section{Publish your work in this journal}

The Journal of Pain Research is an international, peer-reviewed, open access, online journal that welcomes laboratory and clinical findings in the fields of pain research and the prevention and management of pain. Original research, reviews, symposium reports, hypothesis formation and commentaries are all considered for publication.

\section{Dovepress}

The manuscript management system is completely online and includes a very quick and fair peer-review system, which is all easy to use. Visit http://www.dovepress.com/testimonials.php to read real quotes from published authors. 